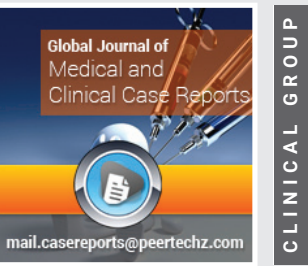

\section{Overview of strategies for writing case report as medical education}

\author{
Yosuke Kakisaka ${ }^{1 *}$ and Franchesca Gabriel ${ }^{2}$ \\ 'Department of Epileptology, Tohoku University Graduate School of Medicine, Sendai, Miyagi, Japan \\ ${ }^{2}$ Section of Neurology, Makati Medical Center, Manila, Philippines
}

Received: 13 April, 2020

Accepted: 18 April, 2020

Published: 20 April, 2020

*Corresponding author: Yosuke Kakisaka, Department of Epileptology, Tohoku University Graduate School of Medicine, 2-1 Seiryo-machi, Aoba-ku, Sendai, Miyagi 980-8575, Japan, Tel: +81-22-717-7343, Fax: +81-22-717-7346; E-mail: kakisuke@mui.biglobe.ne.jp; kakisuke55@gmail.com

ORCID: https://orcid.org/0000-0002-8177-4117

https://www.peertechz.com

Check for updates
Physicians have at least two roles as medical professionals: direct patient management, which involves diagnosis and treatment, and delivering new discoveries acquired from daily clinical activities to patients both in the present and future world. Importantly, these two activities are closely related, and the process of case report writing will integrate them [1]. Here we introduce several activities which will be helpful for case writing.

The first step is to ask oneself "Does my patient have a unique feature that is worth reporting in a scientific paper?" By doing so, physicians will spontaneously be more mindful when seeing their patients. They will be more proactive to take the history, generate differential diagnoses, identify key clinical features, and apply "Occam's razor" (the principle of parsimony) (\#1). The process in which these are performed sequentially is crucial for clinical diagnostic reasoning [2].

Recent development in human communication with advanced technology, such as blog written by patients discussing about his/her disease, may give physicians idea for a correct diagnosis especially when they are clueless about a candidate disease (\#2). In the setting of generating a pathophysiological hypothesis about a patient's condition, a framework of "simplification and analogy" we introduced (\#3) may guide physicians. As a result of these activities, they will be able to correctly diagnose the patient based on appropriate understanding of the patient's disease pathophysiology. At this point, physicians are ready to write a case report in terms of having adequate knowledge about a disease, but some may struggle because of lack of experience in case writing. Recently, we have launched an educational set with didactic lecture for case writing [3] (\#4) and one-to-one, face-to-face writing support for academic writing [4]. The latter starts from introducing basic knowledge about academic writing to providing immediate feedback to a physician's draft with explanation of how descriptions go when applying rules of academic writing (\#5). This educational set for case writing will be helpful for young doctors and students because the activities provide both theoretical foundation and actual writing skill development with hands-on approach. The gap between "just knowing" how to write and "having actual skill" of writing is a hindrance especially for a novice writer. To our best knowledge, our comprehensive program for academic writing with immediate feedback style in the medical field has never been reported. In the future, we should evaluate the educational significance of this approach. We hope that our organized activities for writing case reports will raise young physicians as well as medical students to be skilled not only clinically but also academically.

\section{References}

1. Kakisaka Y, Fujikawa M, Gaillard S (2016) Writing case report: Teaching and tuition techniques, and the improvement of clinical diagnostic reasoning. Int $\mathrm{J}$ Med Student 4: 87-89. Link: https://bit.ly/34Rh7uX

2. Bowen JL (2006) Educational strategies to promote clinical diagnostic reasoning. N Engl J Med 355: 2117-2125. Link: https://bit.ly/2zbBKpZ

3. Kakisaka Y, Fujikawa M, Gaillard S (2016) Structured Didactic Education Program for Writing Case Reports Can Motivate Medical Students. Int J Med Student 4: 131-132. Link: https://bit.ly/2XINESj

4. Kakisaka Y, Fujikawa M, Hino-Fukuyo N, Ishii S (2017) Establishing a structured program for case writing in pediatric neurology medical education: A preliminary study. Brain Dev 39: 364. Link: https://bit.ly/2ynyY0w 